\title{
Product reliability and warranty: an overview and future research
}

Abstract

Reliability and warranty are very important in the context of new products. This paper gives an overview of product reliability and warranty and discusses some issues and challenges for future research.

Key words

Products, reliability, warranty, research.

\section{Confiabilidade e garantia de produto: visão geral e pesquisas futuras}

Confiabilidade e garantia são muito importantes no contexto de novos produtos. Este artigo apresenta uma revisão geral sobre confiabilidade e garantia de produto e discute algumas questões e desafios para pesquisas futuras.

Palavras-chave

Produtos, confiabilidade, garantia, pesquisa.
} 


\section{INTRODUCTION}

Since the industrial revolution started new products have been appearing at an ever increasing pace. The complexity of the products has increased significantly to meet the ever increasing needs and expectations of consumers. Products degrade with age and/or usage and fail when they are unable to carry out their normal functions. Reliability theory deals with various issues such as the understanding of the degradation mechanism, the design of reliable products and the operation of unreliable products.

Consumers need assurance that the product will perform satisfactorily over the useful life of the product. In addition, the legislations are getting more stringent to protect consumer interests. Manufacturer have responded to these challenges by offering warranties and extended warranties. A warranty is a legal contract which requires the manufacturer to either rectify or compensate for all failures occurring within the warranty period. There are many different aspects to warranty and these have been studied by researchers from many different disciplines.

Offering a warranty results in additional costs (referred to as warranty servicing costs or simply warranty costs) to the manufacturer as all failures under warranty need to be either rectified or compensated by the manufacturer. The warranty costs depend on the reliability performance of the product. This in turn depends on several factors some under the control of the manufacturer (such as the decisions made during the design and development of the product) and others under the control of the consumer (such as the usage intensity, operating environment and maintenance). The warranty servicing costs vary from $2-10 \%$ of the sale price depending on the product and the manufacturer. As a result, warranty and product reliability are very important in the context of new product development.

Both warranty and reliability have received a lot of attention over the last fifty years. This paper gives a brief overview of both reliability and warranty and discusses some new issues and the challenges for future research. The outline of the paper is as follows. Section Product Reliability: An Overview deals with an overview of product reliability and Section Warranty: An Overview with warranty. In each section we highlight the important issues and give a historical perspective. Section New Issues and Challenges: Topics for Future Research deals with some issues and challenges as part of future research into reliability and warranty. We conclude with some comments in Conclusions Section.

\section{PRODUCT RELIABILITY: AN OVERVIEW}

Reliability of a product conveys the concept of dependability, successful operation or performance and the absence of failures. It is an external property of great interest to both manufacturer and consumer. Unreliability (or lack of reliability) conveys the opposite. A more technical definition is the following:

The reliability of a product (system) is the probability that the product (system) will perform its intended function for a specified time period when operating under normal (or stated) environmental conditions. (BLISCHKE; MURTHY, 2000)

The reliability of a product gets determined by the decisions made during the pre-production stages (Frontend, Design, Development) and the production stage of the product life cycle. Murthy et al. $(2007 \mathrm{a}-\mathrm{c})$ deal with reliability decision making during the Front-end (or Feasibility) and the Design and Development stages of new product development.

\section{Reliability: different notions}

The design reliability depends on reliability specification at the component level. The reliability of the produced item can differ from the design reliability due to assembly errors and component non-conformance. The reliability of produced items is the "inherent" reliability of the product. The product needs to be transported to the market, and often stored for some time, before it is sold. The reliability at sale for a unit depends on the mechanical load (resulting from vibrations during transport), the impact load (resulting from mishandling), the duration of storage and the storage environment (such as temperature, humidity etc). As a result, the reliability at sale can differ from the inherent reliability. Once an item is sold, it can be either stored for an additional time (if the unit is used as a spare) or put into operation immediately. The reliability performance of a unit in field depends on the length and environment of storage and on several other operational factors such as the usage intensity (which determines the load - electrical, mechanical, thermal, chemical - on the unit), usage mode (whether used continuously or intermittently) and operating environment (such as temperature, humidity, vibration, pollution etc) and in some instance on the human operator. The reliability performance in operation is often referred to as "field reliability". Figure 1 (from MURTHY et al., 2007d) shows how these different reliability notions are sequentially linked and the factors that affect them.

\section{Reliability theory}

Reliability theory deals with the interdisciplinary use of probability, statistics and stochastic modelling, combined with engineering insights into the design and the scientific 
understanding of the failure mechanisms, to study the various aspects of reliability. As such, it encompasses the following topics ${ }^{1}$.

Reliability modelling: Reliability modelling deals with model building to obtain solutions to problems in predicting, estimating and optimising the survival or performance of an unreliable system, the impact of the unreliability, and actions to mitigate this impact.

Reliability analysis: Reliability analysis can be divided into two broad categories: (i) Qualitative and (ii) Quantitative. The former is intended to verify the various failure modes and causes that contribute to the unreliability of a product or system. The latter uses real failure data in conjunction with suitable mathematical models to produce quantitative estimates of product or system reliability.

Reliability engineering: Reliability engineering deals with the design and construction of systems and products, taking into account the unreliability of its parts and components. It also includes testing and programs to improve reliability. Good engineering results in a more reliable end product.

Reliability science: Reliability science is concerned with the properties of materials and the causes for deterioration leading to part and component failures. It also deals with the effect of manufacturing processes (e.g. casting, annealing) on the reliability of the part or component produced.

Reliability management: Reliability management deals with the various management issues in the context of managing the design, manufacture and/or operation of reliable products and systems. Here the emphasis is on the business viewpoint, as unreliability has consequences in cost, time wasted, and, in certain cases, the welfare of an individual or even the security of a nation.

\section{Historical perspective}

Prior to World War II, the notion of reliability was largely intuitive, subjective and qualitative. The use of actuarial methods (involving statistical techniques) to estimate survivorship of railroad equipment began in the early part of the twentieth century (NELSON, 1982, p. 2). In the late 1930's, extreme value theory was used to model fatigue life of materials and was the forerunner to later probabilistic developments.

A more quantitative (or mathematical) and formal approach to reliability grew out of the demands of modern technology and particularly out of the experiences in the second world war with complex military systems (BARLOW; PROSCHAN, 1965, p.1). Since the appearance of this classic book, the theory of reliability has grown at a very rapid rate, as can be seen by the large number of books ${ }^{2}$ and jounals ${ }^{3}$ that have appeared on the subject.

Barlow (1984) deals with a historical perspective of mathematical reliability theory up to that time. Similar perspectives on reliability engineering in electronic equipment can be found in Coppola (1984); on space reliability technology in Cohen (1984); on nuclear power system reliability in Fussel (1984) and on software reliability in Shooman (1984).

\section{WARRANTY: AN OVERVIEW}

A warranty is a manufacturer's assurance to a buyer that a product or service is or shall be as represented. It may be considered to be a contractual agreement between buyer and manufacturer (or seller) which is entered into upon sale of the product or service. A warranty may be implicit or it may be explicitly stated.

Figure 1: Factors influencing field reliability.

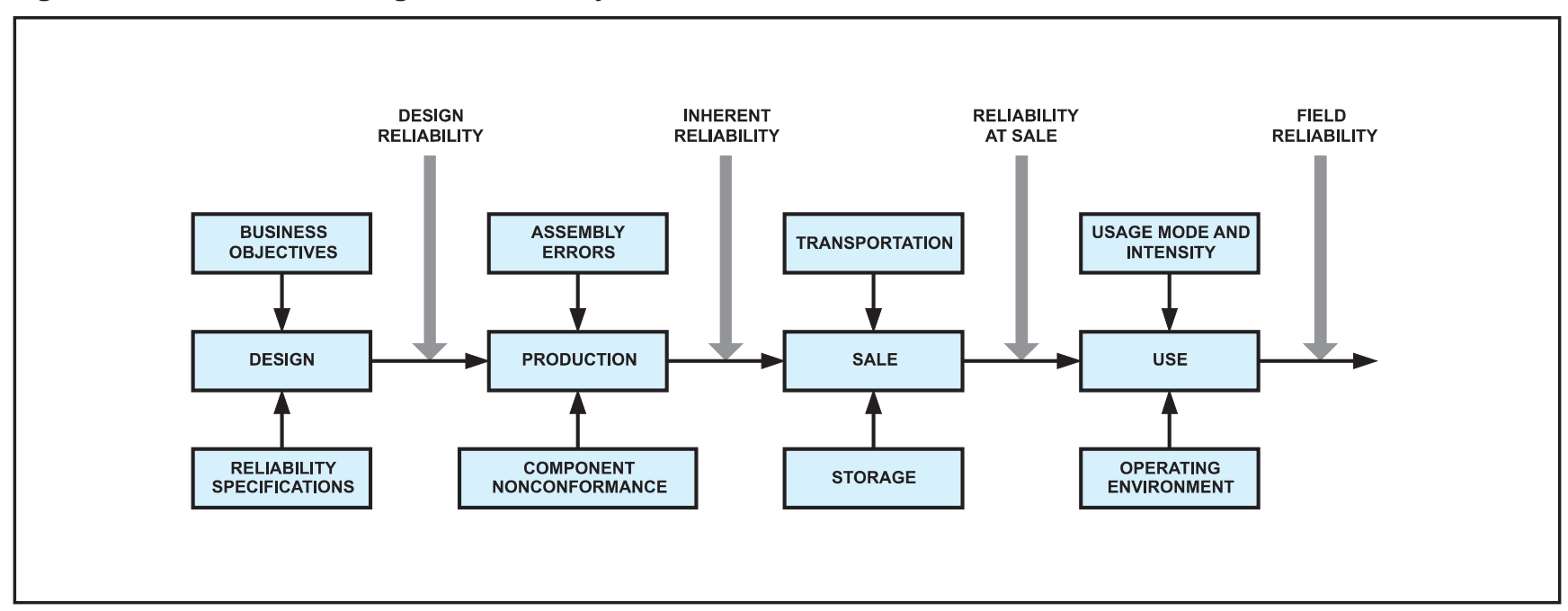




\section{Warranty classification}

There are many different types warranty policies and a classification of these can be found in Blischke and Murthy (1994 and 1996). They can be divided into different categories as indicated below.

- Involving reliability improvement or not

- Single item or group of items (cumulative warranty)

- One-dimensional (limit on age) or two-dimensional (limits on age and usage)

- Renewing or non-renewing

- Base or extended

\section{Base warranties}

Base warranty is integral to the sale and is factored into the sale price. Most standard products are sold with one of the following two warranty policies.

\section{1-D Free Replacement Warranty (FRW) policy}

The manufacturer agrees to repair or provide replacements for failed items free of charge up to a time $W$ (the warranty period) from the time of the initial purchase. The warranty expires at time $W$ after purchase.

\section{1-D Pro-Rata Rebate Warranty (PRW) policy}

The manufacturer agrees to refund a fraction of the purchase price should the item fail before time $W$ (the warranty period) from the time of the initial purchase. The buyer is not constrained to buy a replacement item. The refund depends on the age of the item at failure $(X)$ and it can be either linear or a non-linear function of $(W-X)$, the remaining time in the warranty period and the sale price.

\section{2-D Free Replacement Warranty (FRW) policy}

The manufacturer agrees to repair or provide a replacement for failed items free of charge up to a time $W$ or up to a usage $U$, whichever occurs first, from the time of the initial purchase. $W$ is called the warranty period and $U$ the usage limit. The warranty region is a rectangle in a 2-dimensional plane with age along one axis and usage along the other axis.

\section{Cumulative warranties}

Cumulative warranties are for items are sold as a single lot of $n$ items and the warranty refers to the lot as a whole. The policies are conceptually straightforward extensions of the non-renewing free replacement and pro-rata warranties discussed previously. Let $X_{i}$ denote the service life of item $i, i=1,2, \ldots$ and $S_{n}=\sum_{i=1}^{n} X_{i}$.

\section{Cumulative FRW policy (GUIN, 1984)}

A lot of $n$ items is warranted for a total (aggregate) period of $n W$. The $n$ items in the lot are used one at a time. If $S n<n W$, free replacement items are supplied, also one at a time, until the first instant when the total lifetimes of all failed items plus the service time of the item then in use is at least $n W$.

\section{Reliability Improvement Warranties}

Reliability Improvement Warranty (RIW) policies are offered with complex systems intended for long use. The basic idea is to extend the notion of a basic consumer warranty (usually the FRW) to include guarantees on the reliability of the item and not just on its immediate or shortterm performance. These often include a guaranteed MTBF as a part of the warranty contract.

\section{Reliability Improvement Warranty policy (GANDARA ; RICH, 1975)}

The manufacturer agrees to repair or provide replacements free of charge for any failed parts or units until time $W$ after purchase. In addition, the manufacturer guarantees the MTBF of the purchased equipment to be at least $M$. If the computed MTBF is less than $M$, the manufacturer will provide, at no cost to the buyer, (1) engineering analysis to determine the cause of failure to meet the guaranteed MTBF requirement, (2) Engineering Change Proposals, (3) modification of all existing units in accordance with approved engineering changes, and (4) consignment spares for buyer use until such time as it is shown that the MTBF is at least $M$.

\section{Extended warranties}

The base warranty is integral to the sale and as such factored into the sale price and the customer does not pay anything extra. Extended warranties are optional which customers purchase by paying an extra amount. These are offered by several parties - manufacturers, retailers and independent agencies such as insurance companies etc.

\section{Warranty costs}

There are several different notions of warranty costs. These include (i) warranty cost per unit, (ii) warranty cost over some interval (for example, product life cycle) and (iii) warranty costs per unit time (warranty cost rate). As mentioned earlier, the warranty costs depend on product reliability and the product usage. Figure 2 is simplified characterisation for determining the warranty cost per unit. Blischke and Murthy (1994) discuss the expected warranty costs for a wide variety of warranty policies.

The warranty cost as a fraction of the sale price can vary from $1-10 \%$ depending on the product and the manufacturer. The total warranty costs for General Motors and Ford were over 4 billion dollars each for 2006. Through proper servicing logistics, these costs can be reduced. 
Murthy et al (2004) deals with warranty logistics. One particular issue is the choice between repair versus replace for a failed item under warranty. Murthy and Jack (2007a) deal with this topic.

Extended warranties are similar to outsourcing of maintenance and this topic is examined in Murthy and Jack (2007b).

\section{Issues in warranty}

Because of the diversity of purpose and application, product warranty has received the attention of researchers from many diverse disciplines ${ }^{4}$. As a result, warranty issues have been considered from the following different perspectives

- Historical: origin and use of the notion

- Legal: court action, dispute resolution, product liability

- Legislative: Magnusson-Moss Act; Federal Trade Commission, Warranty requirements in government acquisition (particularly military) and TREAD Act in the USA and the latest EU legislation

- Economic: market equilibrium, social welfare

- Behavioral: buyer reaction, influence on purchase decision, perceived role of warranty, claims behavior

- Consumerist: product information, consumer protection

- Engineering: design, manufacturing, quality control, testing

- Statistics: data acquisition and analysis, data-based reliability analysis

- Operations Research: cost modeling, optimization

- Accounting: tracking of costs, time of accrual
- Marketing: assessment of consumer attitudes, assessment of the marketplace, use of warranty as a marketing tool, warranty and sales

- Management: integration of many of the previous items, determination of warranty policy, warranty servicing decisions

- Societal: public policy issues

As a consequence, the literature on warranty is very large. Blischke and Murthy (1996) deal with these issues in detail. Administration of warranties in the context of government acquisition is discussed in Brenan (1994) and Murthy and Blischke (2005) deal with warranty management in the context of new product development.

\section{Historical perspective}

The origin of the word warranty is interesting. In a study of the origin and history of the concept, Loomba (1996) states:

"The words warranty and guarantee, known to linguists as "doublets," are derived from same original source but traveling to today's English language by different routes. The origins of the word warranty can be traced back to the Old North French word warant and warantie, to the Old High German word werento meaning "protector". During the Middle Ages, the original expressions used included hoc ex condicione, warrantizavit, promisit, and sub tali plevina."

The earliest record of warranty can be found in the Babylonian and Assyrian tablets of the twenty-first century B.C. Since then it has evolved over time and in many

Figure 2: Simple characterisation for warranty cost analysis.

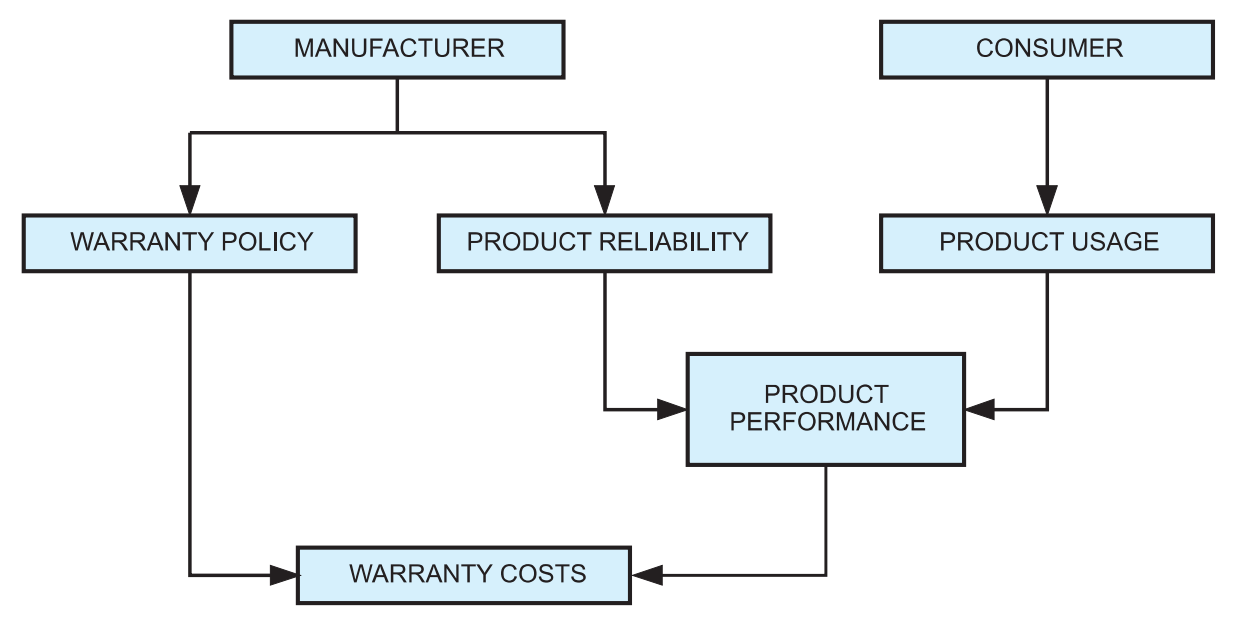


different societies. Some of the key milestones in this evolution were:

i. Roman laws of the fifth century B.C.,

ii. Bavarian laws at the start of the Christian era,

iii. Jewish commercial laws of the second century A.D.,

iv. Hindu religious laws of the fifth century,

v. Islamic laws of the eighth century,

vi. Egyptian formularies of a slightly later period,

vii. Scattered Russian codes of the early tenth century, and

viii. The customs of the church rule of medieval times and customs of the English borough.

The start of the Industrial Revolution in the sixteenth century brought a major change to manufacturing. Components were produced by different businesses and often no single entity was responsible for the product as a whole. Until the first half of the nineteenth century, caveat emptor was the rule and sellers rarely offered any sort of formal warranty on their goods. In the late nineteenth century, warranties were treated as standardized contracts with extremely limited scope ${ }^{5}$.

During the twentieth century, consumer movements have had an impact on warranty. There have been three consumer movements and these are discussed in Blischke and Murthy (1996). The third consumer movement began after the end of World War II and gained momentum in the 1960s. Because of growing concerns for buyers' protection, the notion of express warranty was augmented by another concept, "implied warranty," which basically states that a product must be capable of performing its intended function when used properly and under normal operating conditions. By 1952, every state in the United States except Louisiana adopted what is termed the Uniform Commercial Code (UCC). Several forms of legislation have been enacted during the past few decades to regulate warranties on various products, the most notable such legislation being the Magnuson-Moss WarrantyFederal Trade Commission Improvement Act of 1975 and the TREAD Act of $1999^{6}$.

\section{NEW ISSUES AND CHALLENGES: TOPICS FOR FUTURE RESEARCH}

A framework to study warranty and reliability is given in Figure 3 (from MURTHY; BLISCHKE, 2005). Some of the new issues are the following:

- Outsourcing of design: Here the some component designs are outsourced. If items are not designed properly, it can result in high warranty claims and significantly impact the bottom line of the manufacturer.

- Outsourcing of component manufacture: The warranty costs to the manufacturer of the product can increase significantly if the fraction on nonconforming components is high. There is a trend towards the manufacturer passing on these costs to the component suppliers.

- Warranty servicing: Here the warranty servicing is carried out by an independent agent under a contract. Poor servicing affects customer satisfaction and in turn, the reputation of the product and the manufacturer. Also,

Figure 3: Framework for study of reliability and warranty.

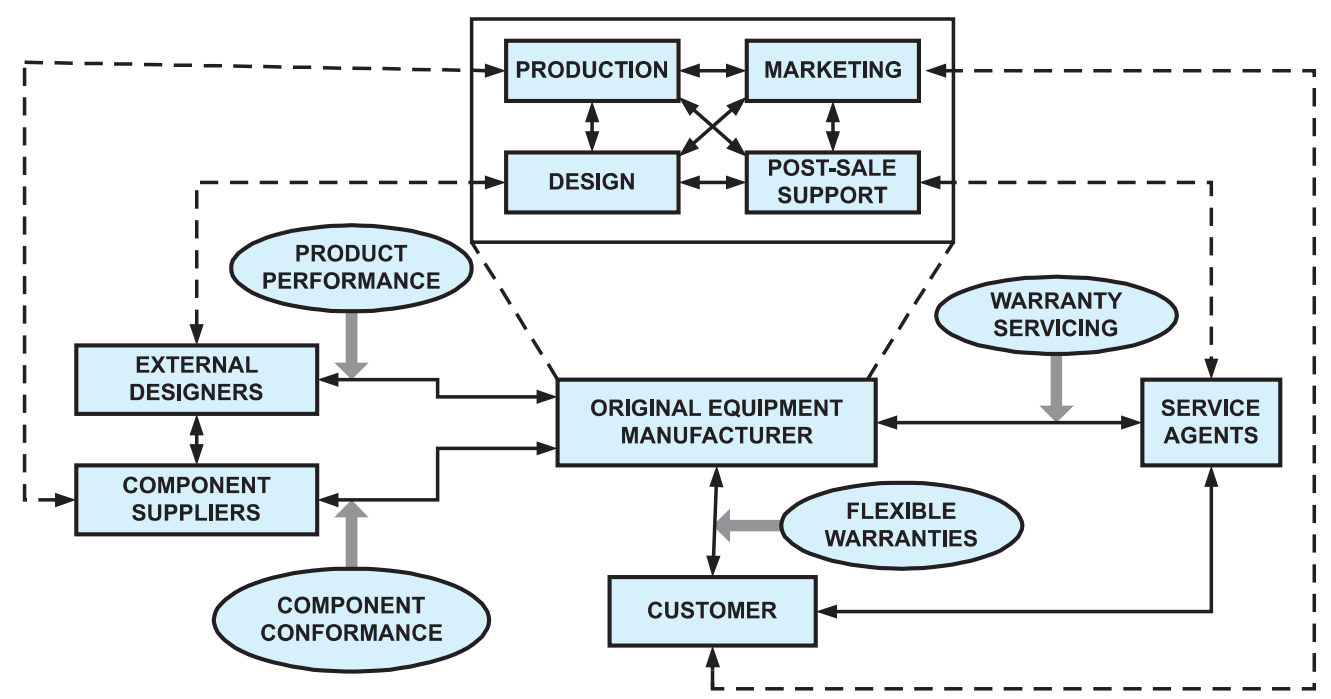


there are potential problems of over-servicing, fraudulent claims etc.

- Flexible (base and extended) warranties: This is to meet the varying usage and risk profiles of consumers.

We now briefly discuss some potential topics for future research.

\section{Warranty servicing and game theory}

Murthy and Ashgharizadeh (1999) deal with maintenance outsourcing as a Stackelberg game formulation. Here the service agent (providing the maintenance) is the leader and the owner of the product (and customer for the maintenance service) is the follower. The service agent provides a set of service options $A_{i}\left(\theta_{i}\right), 1$ $\leq \mathrm{i} \leq n$, and the customer chooses the best option to optimize the customer's goal. This generates the optimal response function $A^{*}\left(\theta_{1}, \theta_{2}, \ldots, \theta_{n}\right)$ as shown in Figure 4. Using this, the service agent then optimally selects the decision variables to maximize the goals of the service agent.

As mentioned earlier, extended warranties are closely related to maintenance out-souring. The study of warranty servicing from a game theoretic viewpoint is an interesting topic for future research.

\section{Warranty management and agency theory}

The framework in Figure 3 indicates three cases involving two parties - manufacturer and an external party. These are: (i) External design houses, (ii) external component suppliers and, (iii) independent warranty service agents. The manufacturer delegates tasks to an external party and the goals (or objectives) of the two are different.

Agency theory deals with the relationship that exists between two parties (a principal and an agent) where the principal delegates work to the agent who performs that work and a contract defines the relationship. Agency theory is concerned with resolving two problems that can occur in agency relationships.

The first problem arises when the two parties have conflicting goals and it is difficult or expensive for the principal to verify the actual actions of the agent and whether the agent has behaved properly or not. The second problem involves the risk sharing that takes place when the principal and agent have different attitudes to risk (due to various uncertainties).

According to Eisenhardt (1989), the focus of the Agency theory is on determining the optimal contract, behaviour versus outcome, between the principal and the agent. Agency theory has also been applied in many different disciplines. For an overview, see Acekere (1993). The different issues involved are indicated in Figure 5 and discussed briefly.

Moral hazard: Moral hazard refers to lack of effort (or shirking) on the part of the agent. The agent does not put in the agreed-upon effort because the objectives of the two parties are different and the principal cannot assess the level of effort that the agent has actually used.

Adverse selection: Adverse selection refers to any misrepresentation of ability by the agent and the principal is unable to completely verify this before deciding to hire the agent.

Information: To counteract adverse selection, the principal can invest in getting information about the agent's ability. One way of getting the desired information is by contacting people for whom the agent has provided service in the past.

Monitoring: The principal can counteract the moral hazard problem by monitoring the actions of the agent. Monitoring provides information about the agent's actual actions.

Information asymmetry: There are several uncertainties that affect the overall outcome of the relationship. The two parties, in general, will have different information to make an assessment of these uncertainties and will also differ in terms of other information.

Risk: This results from the different uncertainties that affect the outcome of the relationship. The risk attitude of the two parties, in general, will differ for a variety of reasons. A

Figure 4: Stackelberg game formulation.

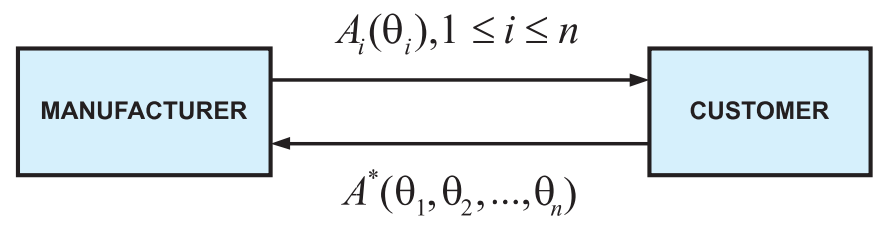


problem arises when this disagreement is over the allocation of risk between the two parties.

Costs: There are various kinds of costs for both parties. Some of these depend on the outcome (which is influenced by uncertainties) but also in acquiring information, monitoring and the administration of the contract. The heart of the principal-agent theory is the trade-off between (i) the cost of monitoring the actions of the agent and (ii) the cost of measuring the outcomes of the relationship and the transferring of risk to the agent.

Contract: The design of the contract that takes into account the issues discussed above is the challenge that lies at the heart of the principal-agent relationship.

The literature on Agency theory is vast. Bulk of them deal with study of various issues using static models. The study of out-sourcing of (i) design, component manufacturing and (iii) warranty servicing using Agency theory require dynamic model formulations. In addition, RIW will be important in the context of design outsourcing and cumulative warranties in the context of component outsourcing. There is lot of scope for new research in this area.

\section{Flexible warranties}

One can define several different notions of flexibility in warranties. A key issue with each notion is the pricing of the warranty. These needs to take into account the response function of consumers. A simple model for flexible warranty is proposed in Jack and Murthy (1977) and there is scope for lot more new research.

\section{Reliability modelling and warranty cost analysis}

As discussed in Section Product Reability: an overview, there are several different notions of reliability - design reliability, inherent reliability and field reliability. One needs to build models that link inherent reliability to design reliability and the affecting factors and similarly for the link between field reliability and inherent reliability. Murthy and Jiang (2007) deals with one such model formulation involving Weibull distributions.

The warranty cost analysis based on field reliability then allows one to assess the impact of these affecting factors on the warranty costs and optimal cost effective strategies to reduce this impact.

\section{Analysis of warranty data}

Warranty data (for products sold with either one- or two-dimensional warranties) provide useful information to estimate field, inherent and design reliabilities. The literature deals mainly with field reliability estimation under different scenarios (see, KARIM; SUZUKI, 2005). The extension of these to estimate inherent and design reliabilities is a potential topic for new research.

\section{CONCLUSIONS}

In this paper we have discussed some new issues and challenges in the areas of reliability and warranty and suggested some topics for research in the future.

Figure 5: Issues in agency theory.

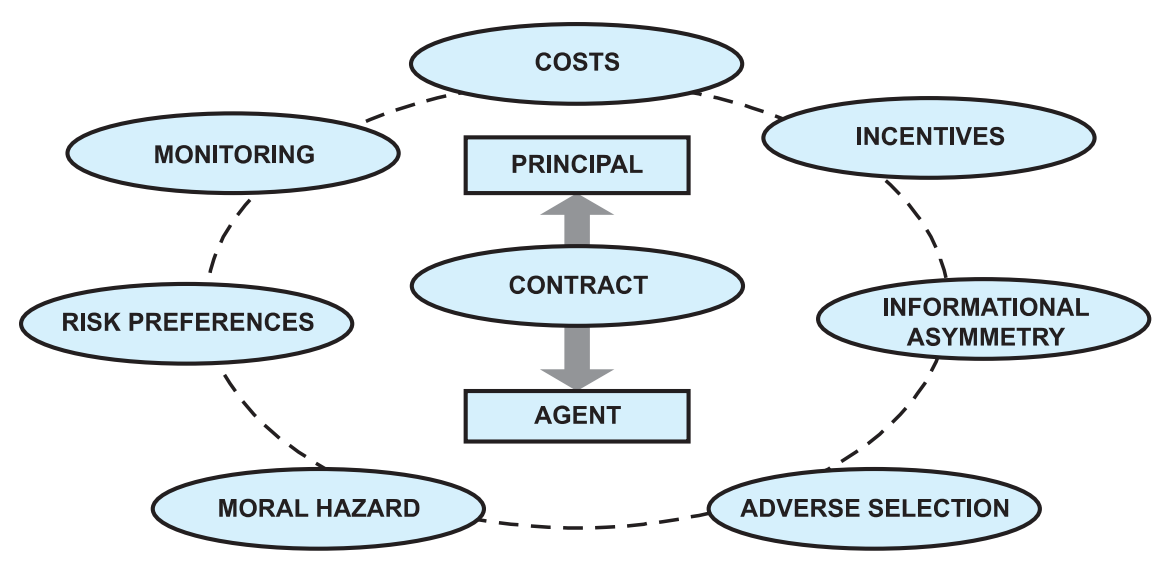




\section{- Notes}

1. Blischke and Murthy (2000) deal with all the different issues in an integrated manner.

2. Some books deal with one issue (for example, estimation, accelerated testing etc) in detail and others deal with more than one issue.
3. These include the following: IEEE Transactions on Reliability, Reliability Engineering \& System Safety, Microelectronics Reliability, Quality and Reliability Engineering, International Journal of Reliability and Applications and International Journal of Quality, Reliability and Management. Papers on reliability can also be found in Operational Research, Statistics, Engineering and other journals.
4. See Djamaludin et al (1996) for a bibliography listing over 1500 papers through 1996. Reviews of the more recent literature on warranty can be found in Thomas and Rao (1999) and Murthy and Djamaludin (2002).

5. Vance (1911) discusses the history of the development of the warranty in Insurance Law.
6. An excellent discussion of express and implied warranties, the MagnusonMoss Act and related issues may be found in "A Businesspersons Guide to Federal Warranty Law," available at http://www.ftc. gov/bcp/conline/buspubs/ warranty.htm

\section{References}

ACKERE A. VAN. The principal/agent paradigm: Its relevance to various fields, European Journal of Operational Research, v. 70, p. 88-103, 1993.

BARLOW, R. E. Theory of Reliability: A historical perspective, IEEE Transactions on Reliability, v. 33, p. 16-20, 1984

BARLOW, R. E.; PROSCHAN, F. Mathematical Theory of Reliability, John Wiley \& Sons, Inc., New York, 1965.

BLISCHKE, W. R.; MURTHY, D. N. P. Warranty Cost Analysis, Marcel Dekker, New York, 1994.

BLISCHKE, W. R.; MURTHY, D. N. P. Product Warranty Handbook, Marcel Dekker, New York, 1996

BLISCHKE, W. R.; MURTHY, D. N. P. Reliability, Wiley, New York, 2000.

BRENNAN, J. R. Warranties. Planning, Analysis and Implementation, McGraw-Hill, New York, 1994.

COHEN, H. Space reliability technology: A historical perspective, IEEE Transactions on Reliability, v. 33, p. 36-40, 1984.

COPPLOA, A. Reliability engineering of electronic equipment: A historical perspective, IEEE Transactions on Reliability, $\mathrm{v}$. 33, p. 29-35, 1984.

DJAMALUDIN, I.; MURTHY, D. N. P.; BLISCHKE, W. R. Bibliography on warran- ties, in Product Warranty Handbook, W.R. Blischke and D.N.P. Murthy (eds), Marcel Dekker, New York, 1996.

EISENHARDT, K.M. Agency theory: and assessment and review, The Academy of Management Review, v. 14, p. 57-74 1989.

FUSSELL, J. B. Nuclear power system reliability: A historical perspective, IEEE Transactions on Reliability, v. 33, p. $41-47,1984$.

GANDARA, A.; RICH, M. D. Reliability Improvement Warranties for Military Procurement, Report No. R-2264-AF, Rand Corp., Santa Monica, CA, 1977

GUIN, L. Cumulative Warranties: Conceptualization and Analysis, Doctoral Dissertation, University of Southern California, Los Angeles, CA, 1984.

JACK, N.; MURTHY, D. N. P. Flexible extended warranties and related optima strategies, Journal of Operational Research, 2007, in print

KARIM, M.R.; SUZUKI, K. Analysis of warranty claim data: A literature review, International Journal of Quality \& Reliability Management, v. 22, p. 667-686, 2005.

LOOMBA, A. P. S. Historical Perspective on Warranty, in Product Warranty Handbook, W.R. Blischke and D.N.P. Murthy (eds), Marcel Dekker, Inc., New York, 1996.
MURTHY, D. N. P.; ASHGARIZADEH E. Optimal decision making in a maintenance service operation, European Journal of Operational Research, v. 116, p. 259 - 273, 1999.

MURTHY, D. N. P.; BLISCHKE, W. R. Warranty Management and Product Manufacture, Springer Verlag, London, 2005.

MURTHY, D. N. P.; DJAMALUDIN, I. Product warranty - A review, International Journal of Production Economics, 79, 231260, 2002.

MURTHY, D. N. P., HAGMARK, P. E.; VIRTANEN, S. Reliability design - III: Product variety and reliability requirements, under review for publication, 2007c.

MURTHY, D. N. P.; JACK, N. Warranty Servicing, in Encyclopaedia of Statistics in Quality and Reliability, F. Ruggeri, R. Kenett and F. Faltin [Editors], Wiley, New York, 2007a, in print.

MURTHY, D. N. P; JACK, N. Warranty and Maintenance in Handbook on Maintenance Engineering and Management, M. BenDaya (ed), Springer Verlag, 2007b, under preparation

MURTHY, D. N. P.; JIANG, R. Product Reliability and Manufacturing Quality: Model Formulation and Analysis, 2007. under review for publication

MURTHY, D. N. P.; OSTERAS, T.; RAUSAND, M. Reliability design - I: An integrated approach, 2007a, under review for publication
MURTHY, D. N. P.; OSTERAS, T.; RAUSAND M. Product Reliability - Specifications and Performance, under preparation for publication by Springer Verlag, London, 2007d.

MURTHY, D. N. P.; SOLEM, O.; ROREN T. Product Warranty logistics: Issues and challenges, Euro. Jr. Oper. Res., 156, 110 $126,2004$.

MURTHY, D. N. P.; VIRTANEN, S. HAGMARK, P. E. Reliability design - II: Linking product reliability to business objectives, 2007b, under review for publication

MURTHY, D. N. P.; XIE, M.; JIANG, R. Weibull Models, Wiley, New York, 2003.

SALEH, J. H.; MARAIS, K. Highlights from the early (and pre-) history of reliability engineering, Reliability Engineering and System Safety, v. 91, p. 249-256, 2006.

SHOOMAN, M. L. Software reliability: A historical perspective, IEEE Transasction on Reliability, v. 33, p. 48-55, 1984.

THOMAS, M. U.; RAO, S. S. Warranty economic decision models: A summary and some suggested directions for future research, Operations Research, v. 47, p. 807-820, 1999

AANCE, W.R. The History of the Development of the Warranty in Insurance Law, The Yale Law Journal, v. 20, p. 523-534, 1911.

\section{About the author}

\section{D.N.P. Murthy}

Division of Mechanical Engineering

The University of Queensland, Brisbane Q 4072 - Australia

Email :p.murthy@uq.edu.au 